\title{
Theorizing Aging in Nepal: Beyond the BiOMEDiCAL MODEL ${ }^{1}$
}

\author{
SARA PARKER \\ Rose KHATRI \\ IAN G COOK \\ BIJAN PANT ${ }^{2}$
}

\begin{abstract}
This paper has in part emerged from work recently undertaken by Parker and Pant under a British Academy funded Small Grant examining the phenomenon of aging in Nepal. This has enabled them to work in collaboration with the Nepal School of Social Work in Kathmandu to both generate locally relevant empirical research on aging and to facilitate the creation of spaces for dialogue on the implications of aging in Nepal. As a result of this project a network of key academics, activists, government policy makers and non-government organizations, both national and international, has been formed. The findings of this study reveal a lack of both empirical data and theoretical development on aging in Nepal. Aging in the west is often viewed from a biomedical perspective where the emphasis is on medical treatment and health and social care arrangements. Biomedicine also dominates international health strategies, organizations, and the funding streams for aid, of which Nepal is a recipient. Whilst longevity is clearly a positive outcome of development, it also presents health and social care dilemmas. This paper provides an opportunity to explore some of these key issues and highlights the need for practitioners, policy makers and the research community in Nepal to provide an open dialogue in which local, culturally appropriate decisions can be developed in the best interest of older people in Nepal.
\end{abstract}

Key words: aging, Nepal, development, biomedical model

1. This paper uses the spelling Aging as this is the most common term used in North America. However in Nepal, as demonstrated by the network Ageing Nepal, it is spelt with 'ageing' and hence is spelt that way when used in quotes or when citing authors/research who adopt this spelling.

2. Acknowledgements - this paper would not have been possible without the support of the British Academy Small Grant which was awarded from April 2011 - 2012. Thanks also to those who reviewed the paper and for participants in Nepal for sharing their thoughts especially to Dr. Bala Raju and staff at Nepal School of Social Work, Mr. Madusudan Subedi from Patan Academy of Health Science, Kirshna M Gautam and staff at Ageing Nepal. 
Résumé. Cet article a émergé en partie des etudes récemment entrepris par Parker et Pant sous par la British Academy qui examinent le phénomène du vieillissement au Népal. Cela leur a permis de travailler en collaboration avec l'École de Travail Social de Népal à Katmandou, à la fois de générer des recherches empiriques du vieillissement qui sont pertinentes au niveau local et de faciliter la création d'espaces de dialogue sur les implications du vieillissement au Népal. À la suite de ce projet, un réseau de professeurs distingués, des activists, les décideurs gouvernementaux, et les organisations non gouvernementales, nationales et internationales, a été formé. Les résultats de cette étude révèlent un manque de données empiriques et les développements théoriques sur le vieillissement au Népal. Vieillissement dans l'ouest est souvent considérée d'un point de vue biomédical où l'accent est mis sur le traitement médical et les arrangements en matière de santé et de services sociaux. La biomédecine domine aussi les stratégies internationales de santé, les organisations et les sources de financement pour aide, dont le Népal est un bénéficiaire. Alors que la longévité est clairement un résultat positif du développement, il présente également des dilemmes pour la santé et des services sociaux. Ce document fournit une occasion d'explorer des questions essentiels et souligne la nécessité pour les praticiens, les décideurs gouvernementaux, et la communauté de recherche au Népal pour fournir un dialogue ouvert dans lequel les décisions locales, qui sont culturellement appropriées, peuvent être développées dans le meilleur intérêt des personnes âgées dans Népal.

Mots clés: Le vieillissement; Népal; développement; biomedical modèl

\section{INTRODUCTION}

ver twenty years ago the question was raised by Birren and Bengston (1988, ix) "Why Theorise about Aging"? They noted that the study of aging was 'data rich', but 'theory poor'; thus alerting to problems of planning and policy making with regard to a rapidly aging population. Clearly, the conceptualization of aging and the development of gerontology have progressed over the intervening years and embrace a multidisciplinary approach (see Bengston and Warner Schaie 1999; Settersten and Angel 2011). Psychologists, sociologists, anthropologists, biologists, as well as medics and social workers continue to theorize about aging and provide an evidence base in relation to the key concerns of an aging world. Although aging is now a global issue (Higo and Williamson 2011); the problematization of aging and its subsequent theoretical development and discourses are dominated by experts in "western" "economically developed" societies. The western view not only dominates 
current thinking and practice, but other contexts are not easily assimilated into the debates, nor clearly understood.

Aging is largely viewed as a negative condition to be managed, and as citizens grow older this management can often be taken out of their hands. As with other groups in society older people can suffer from the effects of social and financial inequalities; some are an extension of inequalities already developed through the life course and can be related to gender, class or ethnicity. However, aging in the western context often adds a further layer of discrimination or exclusion. If wealthy countries struggle to maintain a healthy aging process and provide decent health and social care for its older citizens then how will the emergent longer living populations in low and middle incomes countries such as Nepal manage this process? This project and paper aims to start asking these fundamental questions and find space to develop research and dialogues on aging in the Nepalese context.

\section{Western Concepts and Theories of Aging}

Theories of aging have developed in the West in response to an increased life expectancy and the need to manage the lives of older people. Gerontology is a multi-disciplinary approach to the study of aging which embraces a sociological, psychological as well as a biological basis; though is often dominated by the latter. Health and social policies which affect the aging population are not only dominated by a medical discourse, but are often caught in an ideological struggle between the state and the market place (Powell and Biggs 2003). According to WHO (2012) despite increasing calls for "healthy ageing" and a life course approach; aging continues to be dominated by a "deficit", dysfunctional or biomedical approach.

Social theorists are even critical of their own failure to develop a sound theoretical basis of aging within their own discipline, with too much focus on empiricism. Powell and Hendricks $(2009,5)$ state this is,

... a sad commentary from our point of view, and, of course, our contention is quite the converse; without a sound conceptual grounding and reflexive perspective, social gerontologists build little more than empirical mole hills without any cumulative effect.

This is supported by the work of Alley et al. (2010) who provide an insight into the use of theory in social gerontology publications between 1990 and 2004. Although there was an increase in the use of theory in publications during this period they also note that this was driven by 
theories largely outside of sociology. Social theories which focused on the abandonment of aging relatives in modern societies has long been refuted (Aboderin 2004), though clearly the burden of "intergenerational dependency" remains an important area of research (Higo and Williamson 2011). Powell and Hendricks (2009) through the special edition of the International Journal of Sociology and Social Policy created a space for theoretical discussion and stressed the importance of developing theoretical models in order to give "intellectual respectability to empirical research in social gerontology" (2009a, 6). Social theory has more recently developed around a life course perspective with a focus around human agency, resourcefulness and self-determination (Setterston and Angel 2011) and highlights the growing need for an independent and healthy aging perspective. Inequalities in social and material conditions continue to be an important area of research and theory development in relation to aging; and particularly in relation to gender and ethnicity.

Social discourses on aging continue in the west but what of a country like Nepal? This is a remote, predominantly rural society in transition, in all spheres: economically, socially, politically and culturally. Despite a civil war, which has only recently ended, Nepal has seen life expectancy and other measures of human development improve over the past 10 years. Nepal is clearly progressing through the health transition and with an increase in its elderly population it approaches the 7 per cent threshold towards that significant milestone of an 'aged society' (Cook and Halsall with Parker 2011; Parker and Pant 2009, 2011). Nepal is no longer an isolated mountain nirvana for intrepid backpackers, but a nation on the move, experiencing rapid social change and increasingly becoming part of the globalized world. Can Nepal resist the westernization of all its social institutions, values and traditions, and particularly in relation to an aging society?

Resistance to the western concepts, constructs, ideologies and narratives which dominate discourses on health, welfare and an aging population is an important issue in societies going through rapid social change. Increasingly countries like Nepal are regarded as post-traditional, whereby the norms of a traditional rural based society are rapidly changing in the wake of urbanization, modernization and globalization. Although Nepal was never officially colonized under European imperialism, the impact of modernization since the advent of "development" in the post war consensus has clearly left its mark. Foucauldian analysis of the impact of the grand narratives of development, biomedicine, neo-liberalism and welfarism could be a useful starting point for the study and theoretical development of aging in Nepal. 
It is interesting to note that terminology and language is often determined by the dominant discourse. Aging is a case in point. Academics in North America prefer the spelling Aging to Ageing, although both the United Nations (UN) and the World Health Organisation (WHO) use the latter spelling in reference to internationally based strategies and policies. Moreover, Nepal has chosen to use Ageing, rather than aging, as the official term in its emergent organization and policy documents. In line with this particular journal we will use aging throughout with the exemption when quoting others who use ageing. Although a small thing, it is issues like these which can overpower the quest for self-determination or in the Foucaldian sense "self-care", and the right to "tell our own stories".

\section{The Global Context of Aging}

Aging, like other social phenomena, has globalized and become a key concern in most countries in the $21^{\text {st }}$ century. An aging society is an important outcome of human development or what sociologists might refer to as modernity. From a public health perspective aging is a combination of epidemiological and demographic changes, or a health transition. This transition has seen infant, child, and maternal mortality reduce significantly as well as more general health improvements increase across the whole population. A combination of reducing death rates, birth rates and increasing longevity has resulted in significant demographic shifts towards an aging population. The transition first occurred in industrial societies across Europe and North America, and then moved to countries like Japan, South Korea and Singapore who witnessed rapid change. More recently a range of middle income countries such as China, Ecuador and South Africa have passed the 7 per cent threshold of those aged sixty five or over that marks a society as one that is aged (Cook and Halsall, 2011, Dummer et al. 2011). Moreover, low and middle income countries are witnessing rapid aging with the fastest demographic changes globally (WHO 2012). Current measures of older people (60 years plus) estimate 784 million people globally and a predication of 2 billion by 2050 . In developing countries, current estimates suggest an elderly population represents $9 \%$ with a prediction to $20 \%$ by 2050 (UN 2011).

The global context, in which aging has occurred, is one of rapid economic change that has underpinned concomitant social, spatial, and cultural transformation across the world. Societies have urbanized and industrialized at unprecedented speed, and the neoliberal model of laissez-faire capitalism has become the dominant mode of development. 
This, alongside the combination of technological and scientific progress, has led to many societies, not just in the West, becoming dominated by a medicalized approach, or biomedical model, which has particular significance for aging. This model is intrinsically linked to the spread of modernization, which dominates international health and social development (Tamang and Broom 2010). The model includes the adoption of 'modern healthcare' systems and curative medicine in the pursuit of health through the eradication of disease and improving the quality of life. The biomedical model also underpins the spread of large multinational pharmaceutical industries and has become synonymous with concepts of 'modernity', with more traditional and alternative forms of health knowledge and practice being marginalized, a point we will return to within this article.

\section{Biomedicine ANd Aging}

This discourse on aging is underpinned by concepts and methodologies that are intrinsically rationalistic, modernist and positivist in emphasis. When translated into analytical modes, the emphasis is unfailingly quantitative, based on social surveys that seek to dissect and uncover modes of aging that can provide hope to millions around the globe via stories of "successful" aging, often underpinned by a biomedical fix, that can hold back the "spiral of decline" into which the aging body is stereotypically assumed to descend (Powell 2001, 2005; Powell and Biggs 2000). The medicalization of the body and associated anti-aging measures has become big business, with what Olshansky and Carnes refer to as futurists who contend that:

Yet-to-be developed advances in biomedical technology and the anticipated emergence of nanotechnology are going to radically transform the landscape of human aging and longevity - leading us down a pathway toward physical immortality and eternal youth (Olshansky and Carnes 2009, 731)

Olshansky and Carnes cite a substantial body of evidence to suggest that this perspective largely ignores the biological 'warranty period' that limits the advances that may be possible. However, the dominance of the biomedical model leads to intrusive and invasive medical techniques in which the expert-driven quest to combat aging means that the aging body can become the property of outside experts rather than the self. Further, this model fails to acknowledge the social and cultural contexts 
of aging and the diversity of experience of the life course and becoming older (Vincent 2006).

Aging is not of course just a physical process but also a psychological, social and, for many, a spiritual journey. Cook and Powell (2007, 134) note that there is a tendency in matters of aging "to reduce the social experience of aging to its biological dimension from which are derived a set of normative 'stages' which over-determine the experience of aging". This accompanies certain assumptions about the ways in which people with outward signs of aging are likely to think and behave, often in a negative sense. These negativities are "all explained away by 'decline' and 'deterioration': master narratives that comprise an ageist culture. The effects of the 'decay, decline and deterioration' analogies can be most clearly seen in the dominance of medico-technical solutions to the problems that aging and even an 'aging population' is thought to pose. Here, the bio-medical model has both come to colonize notions of age and reinforce ageist social prejudices to the extent that 'decline' has come to stand for the process of aging itself"' (Cook and Powell 2005, 80-81). This has led to a focus in the 'west' on active aging strategies seeking to either extend the "functionality" of older members of society and or a focus on the medicalization of the body.

Estes and Binney $(1989,587-588)$ explore the dangers and dilemmas posed by medicalization of aging, which has become "such a powerful and pervasive process". The biomedical model often dominates funding streams and policy-making, and has become the "institutionalized thought structure" that underpins the response to aging. Aging, therefore, instead of being perceived within a wider social, behavioural, or cultural context, is seen as a medical category via "medical definition, management, and treatment". These authors do not seek "to diminish the role of either biomedical research or medicine in the eradication of disease", but rather to illustrate the power of the model to define what is after all a natural but also increasingly complex social phenomenon.

\section{Resistance to a Biomedical Model of Aging in the Global South}

The biomedical model has become all too pervasive in the aging agenda though calls for less ethnocentric views are emerging from Asia (Powell and Cook 2009). Despite a long history of traditional medicine in China Cook and Murray (2001) argue that biomedicine has become an important feature of the Chinese response to an aging population. Powell and Cook (2001) note that this has not always been the case and they observe that traditional Chinese society placed older people on a pedestal. They 
were valued for their accumulated knowledge, their position within the extended family, and the sense of history and identity which they helped the family to develop. Respect for elderly people was an integral part of Confucian doctrine, especially for the family patriarch. Also within other religious and cultural contexts, old age is embraced more as a natural stage in the life cycle. An example of this is in the Manu smriti (Hindu law) which considers life to be divided into four stages with each stage equating to approximately twenty five years. Each stage imparts specific duties on people: student hood (childhood), house-holdership (adulthood), retirement (old age), and asceticism (Cohen 1992; Sharma 2004). Such perceptions impact on society's view of when a person becomes "old". This is reflected within Nepali society where many people believe "you are young until you are forty and then you are old".

A recent report by the Nepal School of Social Work (NSSW 2012, 8) highlights, "it is only recently that aging is considered as an economic problem". Like China, aging is traditionally related to social status within the extended family and community. Older people have been valued and respected, they often continue working and contributing to the community in many ways. NSSW $(2012,8)$ also notes, however:

That there is a gendered element to this perception as it is the eldest male member of the family or community who automatically takes the role of head-ship in the family/community. Almost all social and religious activities are guided as well as performed by him. His views and word are taken as the rules and regulations to be followed by the community/family members.

There are also different ethnic and cultural perspectives on aging in Nepal. In some ethnic groups, older people are highly revered and considered almost "god like" at the age of either seventy or eighty four. Amongst the Newari ethnic group, older persons are honoured as "gods" through three different ceremonies called Janku. The first ceremony, Bhim Ratharohan (riding the chariot of strength), is performed when a person attains the age of seventy seventh year, seventh month, seventh day, seventh hours, seventh minute and seventh Pala (Lowest unit of Nepalese chronological time), a second ceremony at eighty four and a third at ninety years (NSSW 2012). However it is important that generalizations are not made based on religious or socio-cultural ethnic practices and those conceptualizations of aging do not over romanticize the views of traditional societies. Some practices such as accusing people, often elderly women, of being "boksi" (witches/ those possessing the evil eye) is a good example of a practice that needs to be challenged (Subedi 2011). Caste and gendered inequalities remain embedded within 
Nepalese society, where Dalit widows are often amongst the most marginalized members of society. This is evident by the relative dominance of unmarried or divorced and abandoned women in the small but growing number of elderly care homes in Nepal (NSSW 2012).

Such conceptualizations of aging are more in line with either a life course or self-care approach and seeing aging as natural process and something to be celebrated: as one nears the end of their life their role in society changes from being a producer and head of household to someone who passes on knowledge and focuses on spiritual matters. In this context elders are considered to be sages, sources of wisdom within the community. It is interesting to note that Ramamurti (2003) refers to old age in India signifying the completion of the stage of establishing a family and rearing children against the back drop of births and rebirths. Cohen's (1992) argues in the article entitled "No aging in India" how the whole meaning of being "old" and a "senior citizen" is a western neo-colonial conceptualization. According to Katz (1996), "prior to industrialization, in India, there was a bestowment that older people had responsible leadership roles and powerful decision-making positions because of their vast 'experience', 'wisdom' and 'knowledge"' (cited Chen and Powell 2011, 14). The instigation of Western based science and rationality imported through development discourses is changing the way aging is viewed in China and India.

The same can be said of Nepal whereby the introduction of terms such as geriatric, senior citizen and elderly population have all been introduced from outside through development discourses. Internal discourses can also dominate when power and status is linked to specific social groups. Like India, Nepal is based on a caste based system. Caste, religion, language, and cultural domination by one group or another is a common feature of south Asia; as such academics, organizations and the policy community need to be mindful of this. In India, for example much of the literature on aging is dominated by a Hinduisation / Hindu perspective. However, research and policy development is not an easy task in a country such as India as Ramamurti $(2003,33)$ notes "where there are so many subcultures with scores of languages and myriad of dialects, carrying out studies across the length and breadth of this country is no easy task". Likewise in Nepal there are more than 130 ethnic groups with at least eight different religions (Tamang and Broom 2010). To some extent Hinduisation or Brahmanisation has dominated economic, social and political development in Nepal. Inequalities in wealth, health and education are key indicators of this domination.

A definition of aging and death that focuses on biological failure and the biomedical model alone unfortunately can "lead to a cultural 
construction of old age whereby diversity and life course is devalued" (Vincent 2006, 681). Such approaches fail to take into consideration the wider socio-cultural context and limit our understanding of the complexities of aging and highlights the need to contextualize these perceptions in order to more fully understand the needs of elders and the opportunities and challenges an ageing population present to policy makers and practitioners. The biomedical model is viewed by many as too positivistic and narrow in its focus and there are calls for a more diverse conceptualization for aging. For example, Engel (1977) highlighted the need for a new approach adopting a bio-psychosocial model within health and social care which adopts a broader understanding of health and well-being. As such, a person would be understood not just as a biological or physical being, but also situated in a social context. In a similar vein, Cook and Powell $(2007,137)$ advocate "the recognition and realization that age is primarily a social constructed problem and also 'the symptomatic deep manifestation of underlying relations of power and inequality that cuts across and through age, class, gender, disability and sexuality'(Cook and Powell 2005, 81)."

In our analysis of Nepal, then, we shall seek to discover, inter alia the extent to which such traditions of deference to, and respect for, the elderly are perpetuated within this changing society. We will also look at how development discourses and particularly biomedical models of aging are being utilized.

\section{Aging in Nepal}

Nepal is a geographically remote, landlocked, predominantly rural, mountainous country in South Asia. However, in the past fifty years, the number of urban settlements has grown from ten to fifty eight, accounting for $18.2 \%$ of the population in 2007 (HDR 2009). It is socially, culturally and environmentally diverse with a population of just over 23 million growing at around 2.4\% a year (HDR 2008). Nepal is one of the poorest countries in South Asia with a per capita income (GNI) of $\$ 540$ per head according to the World Bank (2010) though calculated at $\$ 1160$ by the World Bank (2012). Nepal still ranks 157 on the $\mathrm{Hu}-$ man Development Index (UNDP 2011) irrespective of how its GNI is calculated (HDR 2012). Despite economic growth absolute inequalities persist in Nepal with two out of three Nepalese people living in poverty (HDR 2012). Inequalities are related to place, and particularly urban/ rural dimensions, caste, gender, religion and ethnicity. Nepal has recently emerged from a "People's War" which saw the end of the monarchy in 
2007 following the "People's Movement" and was declared a republic in 2008. Despite the recent conflict and impact on access to basics services such as health care Nepal has made significant progress in addressing a number of the Millennium Development Goals (MDGs). Infant and maternal mortality rates are reducing and Nepal is close to achieving its 2015 targets. These improvements are largely related to reducing birth rates and increasing access to education, family planning and obstetric health care (Barker 2007; Khatri 2011; UNFPA 2008). Life expectancy is improving as a combination of falling birth rates and a reduction in mortality; in 1990, the average life expectancy was just fifty four years, this has now risen to sixty eight point eight years (UNDP 2012). Unlike most other nations, women only began to outlive men in 2008, highlighting the gender inequity in Nepal (HDR 2008).

Improvements in life expectancy are the result of a combination of factors in the political, economic and social arena. The role of modern health care through biomedicine clearly plays a role in this improvement, though as noted before health transitions are not solely the outcome of biomedicine. The key question then is what role can biomedicine play in healthy aging in Nepal? Biomedicine as an agent of development or 'bikas' as it is referred to in Nepal is not fully accepted by all, though it is fair to say that it is a very powerful force in the increasingly urbanized areas of Nepal. The predominant view of 'bikas' as being synonymous with modernity gained currency in Nepal following the overthrow of the Rana regime in the 1950's (Pigg 1992; Shreshta 1995). As Shresta (1995), points out the term 'bikas' meant all things modern and scientific: "the hospital was a sign of bikas... it was brought by white people, the harbingers of bikas .... to us they were obviously economically superior, they spoke the language of bikas, they embodied bikas" (Shreshta 1995, 271). Development has never been a benign idea and all too often shame arises out of the interaction between traditional and modern. Shreshta $(2002,107)$ wrote of how "missionaries mocked our local medical practices, and made us feel ashamed of them". Nevertheless, modern health care systems are aspirations of governments and people alike, they reflect development and modernity, bikas. Cameron $(2008,88)$ feels that "it is not an overstatement to say that 'bikas' stands alongside dharma and karma as a powerful ideology that Nepali people embrace".

However, despite the ideology of bikas the majority of people still rely on traditional or indigenous forms of health care rather than bio- 
medical ${ }^{3}$ (Pigg 1992; Cameron 2008; Bajracharya 2006; Khatri 2006; Phuyal 2006; Tamang and Broom 2010; Subedi 2011).

Cameron (2008) suggests that medical pluralism is highly desirable in Nepal though the state has focused the majority of its efforts on the distribution of bio medically based health resources. Also whilst the Nepalese National Health Policy adopted in 1991 and the Second Long Term Health Plan (1997-2017) emphasized the need to develop a primary health-care system which combined biomedicine with traditional/ indigenous practices according to Tamang and Broom (2010,330) "little progress has been made and the limited state-supported health services are largely biomedical in character". Furthermore, traditional and indigenous approaches are not usually recognized by the formal health sector. This is particular pertinent to older people and an aging society whereby the spiritual role that traditional healers often play are integral to the life course approach to well-being. Older people are often the holders of traditional and indigenous knowledge and practices, an important community resource often lost through modernizing practices and bikas (Khatri 2006).

There is plenty of evidence that the biomedical model of health is spreading, along with the whole panoply of western medical solutions in Nepal. For example, for twenty five years Subedi has been observing a Newari community in the Kathmandu valley (Subedi 2011). He has found that despite the continuation of many traditional beliefs concerning the causes of ill health, medical prescriptions and the use of antibiotics is rampant. Globally biomedicine has increasingly commercialized its activities, although still lauded as a force for good and a means to reduce suffering and improve health, it is now viewed as a market based activity, particularly in low and middle income countries. Bio medically based health care is rarely a cheap option, which means that many people impoverish themselves and family to fund treatment and care, whilst others do without or have to find cheaper services (Subedi 2011). This has consequences for the poorest members of society many of whom are excluded from the potential benefits of the spread of the health care system within Nepal. This is supported by Pande et al. eds. $(2006,179)$ who argue that a " largely biomedical framework for providing health

3. See special edition of Education and Development on Gender Education and Development and indigenous Knowledge and Health Practices from CERID which resulted from a DeLPHE funded link programme http://www.cerid.org/?s=pub\&a=browse $\&$ pub cat $\mathrm{id}=518068395 \mathrm{be} 6826 \mathrm{fd} 1 \mathrm{a}$ $\underline{35 \mathrm{fe} 0 \mathrm{f} 3 \mathrm{de} 88 \& \text { pub parent } \mathrm{id}=0 \& \text { title }=\text { Education }+ \text { Developement }}$

4. A lot of this is anecdotal from discussions with family members, friends and colleagues in Nepal 
care is inadequate to bringing about improvements in the health conditions of the poor and the disadvantaged". However, Subedi (2011) notes that across Nepal, private hospitals and medical colleges have been established in almost all towns, and that the health sector has become one of the most successful private-sector businesses.

The increasing role of biomedically based health care comes with another cost particularly at the expense of traditional and indigenous health care knowledge and practices which continues to play an important role in Nepal (Tamang and Broom 2010). The domination of biomedicine has also reduced the role of another imported health system, Ayurveda. Although of Indian origin, it is firmly embedded in the Nepalese society and has a longer history than biomedicine as a formal health system in the country (Bajracharya 2006). The spread of modern biomedical services is not only internally supported but is also externally driven through funding programmes from international development agencies. In some cases local alternative provisions are being replaced by more "modern facilities". The example of the construction of a hospital, funded by the World Bank, in a place where a long established successful Ayurveda hospital was located in Makaising in the Gorkha district, shows how local facilities are overlooked in service.

This demonstrates how the biomedical model has been replacing traditional and alternative forms of medicine and knowledge in Nepal. Whilst not suggesting that access to modern medicine and health services is not important it is argued here that this needs to be offered alongside other forms of health and social care. Bhasin (2003) argues that people are increasingly treated as objects in the biomedical approach; and given the lack of acknowledgement to wider social or cultural contexts Estes and Binney $(1989,596)$ conclude that "for the sake of the elderly and for those who will age, the biomedicalization of aging must be resisted". Shreshta $(1995,277)$ calls for us to "unlearn the western values and development thinking which have infested our minds. However unlearning is not complete without relearning. So let us relearn". Challenging dominant discourses and proposing alternative explanations however requires systematic research and dialogue to take place amongst those seeking to challenge the status quo. This paper will now turn to consider these issues in relation to meeting the health social care needs of an aging population in Nepal. 


\section{Healthy Aging in Nepal: Data Poor, Theory Poor}

The emergence of a significant aging population in Nepal has only occurred in the past decade and is urgent need of research (Parker and Pant 2009, 2011). In many ways the situation in Nepal reflects the Indian situation in the early 1990s when the challenge of meeting the health and welfare needs of an aging population first emerged. Ramamurti (2003) stressed the need for better research and data to understand and plan for these needs. Whilst agreeing with this, it also should also be acknowledged that empirical data is not collected in a theoretical vacuum and care needs to be taken as to what drives the research agenda. Adopting a medical model of aging comes at a price, as health care need and demand increases with age so does the cost of provision, along with questions of who pays. Aging has only recently entered the policy arena in Nepal and is clearly not a priority in nations focused on Millennium Development Goals. As such, Nepal has limited resources and finances to allocate to research in this area and thus the interest in aging relies on a small, though diverse range of groups including medical practitioners, human rights activists, advocacy workers and social gerontologists (Parker and Pant 2011). Whilst this group is passionate and diverse it is also small and underfunded. Clearly without more support the aging agenda will be dominated by the external development interests.

According to Longino and Murphy (1995) gerontology has been trapped in a bio-medical thrall until the recent emergence of critical and reflexive theories. This is important for Nepal and as Bala Raju Nikku states "it is useful to look at how disciplines and professions, both the Global North and Global South, such as social work, gerontology, sociology, medicine, philosophy, and political science look at aging issues" (Nikku 2012). He goes on to discuss that researchers from these disciplinary backgrounds often draw on different methodologies and focus on different questions to explore aging issues. He also adds that "different agents also use different sets of concepts and terminologies to explain the same phenomenon!" This highlights the need for open dialogue and culturally appropriate research on aging in Nepal.

\section{Identifying Resistance to the Biomedical Model in Nepal}

Parker and Pant have been involved in a small but pioneering study of aging in Nepal funded by the British Academy in conjunction with NSSW based in Kathmandu. The aims of the project were to assess the state of services for the elderly and provide an overview of the research 
into this emerging area. Research studies in this area are thin on the ground but the project was able to facilitate a number of research studies undertaken by students from the department (NSSW). The project also facilitated a one day dissemination conference in December 2011, to which the leading local experts in the field were invited. This small scale project highlighted both a lack of research, and demonstrated a need to develop a network of interested groups such as academics, activists and the media as well as policy makers. Bala Raju Nikku (Head of NSSW) commented that:

This is the first time that this topic has been explored within the field of social work in Nepal, as social work in itself is in its infancy in Nepal. This research funding has put the issues of Ageing onto the agenda and encouraged our students to undertake research in this field. It has also led us to realize that we need to address this issue and develop a course specifically focused on exploring the social welfare needs of an ageing population and to consider the most appropriate theoretical models (speaking in December 2011 at the Ageing Seminar, Kathmandu ${ }^{5}$ ).

It is difficult to compare Nepal to other countries within South Asia, such as India that have a longer history of research and development on aging. Nepal has a limited number of academics, research institutions and funding streams in this area. One of the main findings of the British Academy funded project was the lack of information on the situation of the elderly in Nepal and the urgent need for relevant data to be collected. To date there have been no comprehensive surveys of the elderly in Nepal to identify the key challenges that they face and therefore there is a lack of data on which to help develop credible answers to current problems. As a result, it has seriously jeopardized the formation of policies related to an aging population in Nepal. The issue of aging however is becoming more prominent and recently Tribhuvan University and UNFPA (United Nations Fund for Population Activities) have conducted a survey on the "health care needs of a rural community" in a small location outside of the Kathmandu valley, and this may provide more evidence to address such concerns. Any future research must consider questions and methods very carefully and ensure the participation of elders in this process. A good example is provided by NEPAN who have been working at the local level to get the voices of the older community heard and on to policy agendas. This is promising and needs to be supported to strengthen the link between activists and policy makers in Nepal.

5. Report is forthcoming 


\section{Data Poor, Theory Poor - Ensuring that Theorization is Grounded}

The presence of a significant aging population is a relatively recent phenomenon in Nepal, and is clearly not a priority in human development compared with maternal, child, and infant mortality for example. Nevertheless there is a small, but diverse, network of people working in the field and working together to address the deficits in knowledge and research in this area. In recent years the Geriatric Centre Nepal (GCN) has been at the forefront of data gathering in the field of aging in collaboration with eminent Nepali scholars such as Krishna M. Gautam (GCN), Hom Nath Chalise (social gerontologist) Manohar Upreti (master trainer on ageing issues/ medical expert) and Madusudan Subedi (medical anthropologist). The work by Chalise and Brightman (2006) highlights the problem of an aging population in a society that is going through rapid political and social change. The eroding of traditional family structures, rural life and religious values all play a part in the problematization of an aging population. Recent research has also shown an increase in organisations focused on care of the aging, such as Old Age Homes (GCN 2010; NSSW 2012), Help the Aged International, NEPAN and Ageing (GCN 2010; Parker and Pant 2009, 2011).

Research by GCN (2010) highlights the changing perceptions of older citizens within the wider Nepalese society; reports of cases of elder abuse as well as providing a discussion on how best to address the needs of an aging population in the context of Nepal. Whilst there are a limited number of studies on health and social care issues of older people in Nepal (see Parker and Pant 2011 for an overview); they are at least multidisciplinary and draw on a range of experts. The lack of external and local funding in this area has meant that most of the research has been undertaken by national experts and has not been dominated by external theoretical models and so to some extent it can be argued that the lack of research in this area has enabled the conceptualization of aging to be free from a biomedical domination. By comparison countries such as China where there has been a longer tradition of research and research institutions, the bio-medical model has been highly influential (See Cook and Powell 2007). The focus of research in Nepal has been related to active aging and identifying measures to enable older people to remain in their own homes. A good example of the resistance to the biomedical model is the renaming of the Geriatric Centre to Ageing Nepal in 2011. This is also reflected in the choice of name chosen for the recently formed network of agents and agencies involved in this field, Third Age Concern Group. 
It would be unfair to say that research in Nepal is conducted in a theoretical vacuum. It would be more accurate to say that the multi-disciplinary research in Nepal has not yet created a space to engage in the theoretical discourses that surround aging. Despite the recent increase in research and networks in this area, as discussed in Parker and Pant (2011) there has been a lack of dialogue around theoretical underpinnings, assumptions and approaches in research methodology and policy development. There are even less funds available to designate research and time to the theoretical discourses of aging in Nepal. As Krishna Gautam, head of Ageing Nepal, a leading NGO working with and for older people in Nepal revealed, "we don't know anything about the biomedical model so far but what I know is that aging issues are more about humanistic rather than medical concerns; this is why we changed our organization's name from Geriatric Centre Nepal to Ageing Nepal" (Gautam 2012). Dr. Hom Nath Chalise, a gerontologist and leading scholar in the sector feels that the biomedical model is too limited and that "social health is the right term to address aging issues in Nepal". He further added, "It is a socio-cultural matter, loneliness creates psycho-physical problems". This reflects to some extent the impact of modernity and globalization on Nepal, whereby migration of younger people to urban areas and overseas has resulted in a fractured society. Traditions of multigenerational co-residence are diminishing, though to what is extent is not known and could make for an interesting social research project.

This study has identified awareness amongst national experts and policymakers in Nepal that there are limits to the use of a biomedical model in the healthy aging agenda. For some this model is seen as a 'foreign concept' and is something they have not considered, and in which there is little interest; whilst others welcome the development of new and more contextualized fields of knowledge in this area (NSSW 2012). Also the study has identified both a lack of data and theoretical development in the field of aging in Nepal and the need for a strong nationally based approach which links researchers in this area together. To some extent the grant has facilitated this by enabling a network of key actors in $\mathrm{Ne}-$ pal to meet and lead to the formation of the 'Third Age Concern Group' network. This is an important development as civil society organisations or NGO's are increasingly seen as important players in the care and advocacy roles for older people in post-traditional societies (Angel 2011).

As part of the study the authors had the opportunity to network and interview key academics and practitioners working in the field of aging and interview policy makers. In one such interview the Joint Secretary, Ministry of Women, Children and Social Welfare, provides an insight into the desire to move beyond the biomedical model. The Joint Secre- 
tary remarked "all I know is we haven't mentioned or realized to mention it [the biomedical model] in any of our policies as this is new terminology." He further stressed that "we will not deal with or treat our aging health issues as only a medical problem it is also a socio-cultural issue too. However, they [older people] do have some medical issues as well; this is why our policy aims to set up a geriatric ward in each government hospital, and we are going to start from Patan hospital soon" (Adhikary 2012, personal communication). The need for government to work with wider society to tackle issues relating to an aging population was also noted "so far we (the government) are only able to offer very limited services to the aging people such as old age pension, discount in the public transportation, trying to allocate their health needs through establishing a geriatric ward in the public hospital". He further added "I know these are not enough but we cannot ignore our limitation and constraint as well, this is why we are making civil society (NGO) friendly policy in the aging sector then we can work jointly to address older people health needs not only in Kathmandu, but also throughout the country".

Similar to other low and middle-income countries trying to resist westernization of their health and social beliefs Nepal has to be pragmatic. An aging population very often comes with increasing health and social care needs. How this is managed and provided for is the key issue. This might require specialized hospital care and/or improved community care. Subedi (2012) feels this is an important point and that such care needs special training for the family members in general and community volunteers in particular. He suggests that such training could be facilitated at the Village Development Committee (VDC) level, "probably based on Female Community Health Volunteers (FCHVs) in the first instance, although in the longer term, ideally males too would be engaged in caring activities". In addition, Mothers' Groups who are already actively engaged in community health activities could be trained, with a view to engaging fathers groups in healthy aging activities. The environmental and cultural context of aging (see Phillipson 2011) is another interesting area of potential research in a country going through rapid social change whilst still trying to hold on to traditional identity and values and resist wholesale modernization and the grand narratives of the west. Whatever way Nepal tackles policy issues related to the welfare of elders it must include their voices and those who advocate on their behalf. 


\section{Conclusions}

The key insights from the British Academy project have been that older people in Nepal are amongst the most neglected groups and there is a lack of policy development and service provision to meet the needs of an aging population. Government policies related to the welfare needs of the aging population are developing, and private and charitable old age homes are being established however more research is needed to enable these providers to offer high quality care that is affordable and culturally appropriate. The work of organisations such as Ageing Nepal are to be applauded for bringing the plight of older people into the media spotlight and there is a need for further research to be undertaken to evaluate the challenges of providing services, such as health care and social services for Nepali elders.

Based on the interactions between key stakeholders researching and working in the field of aging over the past year we come to the view there is an important role to be played by academics such as social gerontologists and medical anthropologists as well as health and welfare service providers, and advocacy groups, NGO's and policy makers. We concur with Subedi (2012) that there is a need for Nepal and Nepali academics and practitioners to develop their own theories of aging as the biomedical model is both outdated and ignores cultural contexts and diversity in human populations. What is needed is a model that incorporates social, psychological, cultural and medical needs and acknowledges the intersectionality and diversity of aging.

The British Academy Small Grant has enhanced the research capacity of staff and students at NSSW and has led to the establishment of a multi-disciplinary aging network in Nepal 'The Third Age Concern Group'. The group, whilst in its infancy, creates an ideal space for discourses on aging and the opportunity for more locally relevant theoretical models to be discussed. Ideally, this will allow the key stakeholders in Nepal to create their own identity and approach to ageing for themselves. These models will of interest to others within the South Asia region and further afield where alternatives to the dominant western based narratives of biomedicine and health and social care arrangement are being sought. This research has highlighted the need for further funds to be allocated to this emerging field to enable examples of good practice to be drawn, networks to expand and develop and future collaborative research to take place. 


\section{REFERENCES}

Aboderin, Isabella. 2004. Modernisation and ageing theory revisited: Current explanations of recent developing world and historical shifts in material family support of older people. Ageing and Society 24:29-50.

Adhikary, Upendra P. 2012. (Joint Secretary, Ministry of Women, Children and Social Welfare, Government of Nepal) Interview by Dr Bijan Pant, April.

Alley, Dawn E., Norella M. Putney, Melissa Rice, and Vern L. Bengtson. 2010. The increasing use of theory in social gerontology: 1990-2004. The Journals of Gerontology B 67(4):583-590.

Angel, Ronald J. 2011. Civil society and elder care in post traditional society. Pp. 549-562 in R.A. Settersten and J.L. Angel, eds., Handbook of Sociology of Aging. New York: Springer.

Bajracharya, Madhu Bajra. 2006. Traditional Ayurveda, the indigenous knowledge and health practice in Nepal. Education and Development 22:90-97. Retrieved May 2012 http://www.cerid.org/?s=pub\&a=browse\&pub cat id $=518068395 \mathrm{be} 6826 \mathrm{fd} 1 \mathrm{a} 0 \mathrm{f} 35 \mathrm{fe} 0 \mathrm{f} 3 \mathrm{de} 88 \& \mathrm{pub}$ parent $\mathrm{id}=0 \&$ title $=$ Educatio n+Developement.

Barker, Carol E. 2007. Support the safe motherhood programme in Nepal: An integrated approach. Reproductive Health Matters 17(33):45-50.

Bengston, V.L. and K. Warner Schaie, eds. 1999. Handbook of Aging. New York: Springer

Bhasin, Kamala. 2002. Gender and Sustainable Development. Kathmandu: Shtrii Shakti.

Birren, James E. and Vern L. Bengston eds. 1988. Emergent Theories of Aging. New York: Springer.

BK, Bishnu Kumari. 2009. Reborn at 60. Feature report on UNFPA web site. Retrieved May 2012 http://nepal.unfpa.org/en/stories/story.php?ID=21.

Cameron, Mary M. 2008. Modern desires, knowledge control, and physician resistance: Regulating Ayurvedic medicine in Nepal. Asian Medicine 4(1):86-112.

Chalise, Hom Nath and James D. Brightman. 2006. Aging trends: Population aging in Nepal. Geriatrics and Gerontology International 6(3):199-204. Retrieved 22 July 2012 from http://onlinelibrary.wiley.com/doi/10.1111/ j.1447-0594.2006.00347.x/abstract.

Chen, Sheying and Jason L. Powell. 2011. Aging in China: Implications to Social Policy of a Changing Economic State. New York: Springer.

Cohen, Lawrence. 1992. No aging in India: The uses of gerontology. Culture, Medicine and Psychiatry 16(2):123-161.

Cohen, Lawrence. 1998. No Aging in India: Alzheimer's the Bad Family and other Modern Things. Berkeley: University of California Press. 
Cook, Ian G. and Jamie Halsall. 2011. Aging in Comparative Perspective. New York: Springer.

Cook, Ian G. and Jamie Halsall with Sara Parker. 2011. Aging in Nepal. Pp. 59-66 in Ian G. Cook and Jamie Halsall, Aging in Comparative Perspective: Processes and Policies. New York: Springer.

Cook, Ian G. and Geoffrey Murray. 2001. China's Third Revolution: Tensions in the Transition to Post-communism. London: Curzon.

Cook, Ian G. and Jason L. Powell. 2005. China, aging and social policy: The influences and limitations of the bio-medical paradigm. Journal of Societal and Social Policy 4(2):71-89.

2007. Ageing urban society: Discourse and policy. Pp. 126-142 in F. Wu, ed., China's Emerging Cities: The Making of New Urbanism. London: Routledge.

Dummer, T.J.B., Jamie P. Halsall, and Ian G. Cook. 2011. Longevity in the $21^{\text {st }}$ century: A global environmental perspective. International Journal of Society Systems Science 3(4):307-324.

Engel, George L. 1977. The need for a new medical model: A challenge for biomedicine Science. 196 N4286 p129 - 196

Estes, Carol L. and Elizabeth A. Binney. 1989. The biomedicalization of aging: Dangers and dilemmas. The Gerontologist 29(5):587-596.

Geriatric Centre Nepal 2010. Status Report on Elderly People (60+) in Nepal on Health, Nutrition and Social Status Focusing on Research Needs. Report for Government of Nepal Ministry of Health and Population, Kathmandu. Retrieved 6 July 2010 http://www.globalaging.org/health/ world/2010/nepal.pdf.

Guatam Krishna M. 2012. Interview with Bijan Pant and email correspondence May-June 2012.

HDR. 2008. Human Development Reports Statistics. Retrieved 1 February 2009 http://hdr.undp.org/en/statistics.

Build your own tables. Human Development Report. Retrieved 12 October 2010. http://hdrstats.undp.org/en//buildtables/\#\#.

- Nepal Country Profile. Retrieved 16 July 2012 Retrieved May 2012 http://hdrstats.undp.org/en/countries/profiles/NPL.html.

Higo, Masa and John B. Williamson. 2011. Global aging. Pp. 117-130 in R.A. Settersten and J.L. Angel, eds., Handbook of Sociology of Aging. New York: Springer.

Khatri Rose. 2011. Gender mainstreaming and maternal mortality in Nepal. Education and Development Special Edition 75-89 Kathmandu Retrieved August 2012 http://www.cerid.org/?s=pub\&a=browse\&pub cat_id=518 068395 be6826fd1a0f35fe0f3de $88 \&$ pub parent id=0\&title=Education + Developement. 
Khatri, R. 2006. Indigenous health knowledge in Nepal: Exploring the way forward to promote, protect and sustain. Education and Development 75-90. Retrieved May 2012 http://www.cerid.org/?s=pub\&a=browse\&pub cat id $=518068395 \mathrm{be} 6826 \mathrm{fd} 1 \mathrm{a} 0 \mathrm{f} 35 \mathrm{fe} 0 \mathrm{f} 3 \mathrm{de} 88 \& \mathrm{pub}$ parent $\mathrm{id}=0 \&$ title $=$ Educatio n+Developement.

Longino, Charles F. and John W. Murphy. 1995. The Old Age Challenge to the Biomedical Model: Paradigm Strain and Health Policy. Amityville, New York: Baywood Press.

Nepal School of Social Work. 2012. Aging in Nepal: Situational Analysis and Role of Service Providers (Government, NGO's and Volunteer Organization in meeting the needs) Aging report from British Academy Small Grant available at http://www.ljmu.ac.uk/HSS/119366.htm.

Nikku, Bala Raj. 2012. Interview with Dr Sara Parker via email August 2012 personal communication.

Olshansky, S. Jay and Bruce A. Carnes. 2009. The future of human longevity. Pp. 731-745 in P. Uhlenberg, ed., International Handbook of Population Aging. New York: Springer.

Pande, Sriram R., Shawna Tropp, Bikash Sharma, and Yuba Raj Khatiwada, eds. 2006. Nepal Reading in Human Development: A UNDP Report. Retrieved Sept 2012 http://www.undp.org.np/uploads/publication/Nepal_Readings_in_HD_20110609030321.pdf.

Parker, Sara. and Bijan Pant. 2009. Aging in Nepal: Emerging issues and challenges. Pp. 89-108 in J.L. Powell and I.G. Cook, eds., Aging in Asia. New York: Nova Science Publishers. 2011. Longevity in Nepal: Health, policy, and service provision challenges. International Journal of Society Systems Science 3(4):333-345.

Phillipson, Chris. 2011. Developing age friendly communities; New approaches to growing old in urban environments. Pp. 279-295 in R.A. Settersten and J.L. Angel, eds., Handbook of Sociology of Aging. New York: Springer.

Phuyal, Narendra. 2011. Indigenous people of Nepal and their health practices. Education and Development Special Edition 69-74 Kathmandu Retrieved August 2012 http://www.cerid.org/?s=pub\&a=browse\&pub cat

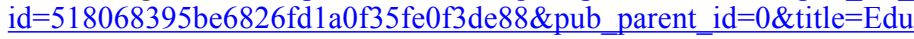
cation+Developement.

Pigg, S.L. 1992. Inventing social categories through place: Social representations and development in Nepal. Comparative Studies in Society \& History 34(3):491-513.

Powell, Jason L. 2001. Theorizing gerontology: The case of old age, professional power and social policy in the United Kingdom. Journal of Aging and Identity 6(3):117-135. 2005. Social Theory and Aging. New York: Rowan and Littlefield.

Powell Jason L. and Simon Biggs. 2003. Foucauldian gerontology: A methodology for understanding aging. Journal of Sociology 7(2). Retrieved July 2012 http://www.sociology.org/content/vol7.2/03 powell_biggs.html. 
2000. Managing old age: The disciplinary web of power, surveillance and normalisation. Journal of Aging and Identity 5(1):3-13.

Powell, Jason L. and Ian G. Cook. 2001. Understanding Foucauldian gerontology: The Chinese state and the surveillance of older people. International Journal of Society, Language and Culture 8(1):1-9. ed. 2009. Aging in Asia. New York: Nova Science Publishers.

Powell, Jason L. and Hendricks, Jon 2009. Theorizing in social gerontology: the raison d'être. Journal of Sociology and Social Policy 29(1/2): 5-14

Ramamurti, P.V. 2003. Perspectives of research on aging in India. Journal of Aging and Social Policy 15(2-3):31-43.

Rowles, Graham D. 1988. What's rural about rural aging? An Appalachian perspective. Journal of Rural Studies 4(2):115-124.

Settersten, Richard A. and Jacqueline L. Angel, eds. 2011. Handbook of Sociology of Aging. New York: Springer.

Sharma, Rajendra K. 2004. Indian Society: Institutions and Change. New Delhi: Atlantic Publishers and Distributers.

Sharma, Sharan Prakash. 2010. Politics and corruption mar health care in Nepal. The Lancet 375(9731):2063-2064. Retrieved 12 June 2010 http:// www.thelancet.com/journals/lancet/article/PIIS0140-6736(10)60945-2/ fulltext.

Shrestha, A. 1993. A study on the supply and demand for non formal education in Nepal. World Education, Kathmandu, Nepal.

Shrestha Nanda. 2002. Becoming a development category. Pp. 266-277 in S. Schech and J. Haggis, eds., Development: A Cultural Studies Reader. Oxford: Blackwell.

Shrestha Srijana and Steven Zarit. 2012. Cultural and contextual analysis of quality of life among older Nepali women. Journal of Cross-Cultural Gerontology 27(2):163-182.

Subedi, Bhim Prasad. 2005. The aged and the marginal: Social geography of older people in Nepal. The Himalayan Review 35-36:1-18.

Subedi, Madhusudhan. 2012. Interview with Sara Parker and email correspondence May - June 2012.

2011. Illness, causation and interpretation in a Newar town. Dhaulagiri Journal of Sociology and Anthropology 5:101-120.

Tamang, Asha Lal and Alex Broom. 2010. The practice and meanings of spiritual healing in Nepal. South Asian History and Culture 1(2):328-340.

UN. 2011. World population prospects:The 2010 revision highlights. Retrieved Aug 2012 from http://esa.un.org/wpp/Documentation/pdf/WPP2010 Highlights.pdf.

UNFPA Nepal. 2008. Gender overview. Retrieved 25 January 2009 http://www. unfpanepal.org/en/programmes/gender.php. 
Vincent, John A. 2006. Aging contested: Anti-aging science and the cultural construction of old age. Sociology 40(4):681-698.

WHO. 2012. Knowledge translation on ageing and health: A framework for policy development. Geneva WHO Retrieved June 2012 http://www. who.int/ageing/publications/knowledge translation/en/index.html.

World Bank. 2010. Nepal Country overview. Retrieved December 2011 http:// www.worldbank.org/en/country/nepal/overview.

Sara Parker (Senior Lecturer, Sociology at Liverpool John Moores University) has over 20 years of action research experience in Nepal in the areas of gender, participatory development, education, ageing and visual methods.

Rose Khatri (Programme Leader for Public Health at Liverpool John Moores University) has a teaching and research interest in public health approaches and development in low resource settings; ageing in low \& middle income countries and indigenous knowledge.

Ian G. Cook (Emeritus Professor of Human Geography at Liverpool John Moores University) main interests include Chinese urbanisation, health issues in China and globally, social anarchism and international gerontology.

Bijan Pant (Visiting Professor at Lodz University Poland and Honorary Research Fellow at Liverpool University) has been involved in a variety of research projects in cross country/culture work experience and knowledge within diverse socio-economic and fragile geo-political contexts. 